\title{
WATER AND WASTE INTERACTIONS IN A MODERN LANDFILL SITE
}

\author{
Marcia Marques \\ Rio de Janeiro State University UERJ, Brazil
}

\section{Introduction}

In a modern society employing recycling and re-use based on the closed-loop philosophy, a landfill site is more like an industrial facility than a mere final waste disposal site. Examples of activities carried out at a modern landfill site are: sorting of slag from incineration residues for subsequent recycling; composting of garden waste and polluted soil or sludge; wood chipping for fuel production; crushing and sorting of construction and demolition waste for road construction and anaerobic decomposition of organic waste for biogas extraction and; landfilling. All these activities have transformed modern landfill sites into large facilities, which have been called "waste management parks" (Marques, 2000). Within this perspective, different interactions between waste and water are expected to generate different potential sources for pollution of surface water as well as groundwater.

Leachate is considered the most important (often the only) form of pollutant transport by water at landfill sites. As a consequence, research and environmental monitoring programmes have traditionally focused mainly on leachate and, occasionally, on the overland flow from covered landfills. A reduction in the potential pollution of landfills is forecasted due to changes in the composition of the waste landfilled, particularly in the EU state members. In the future waste will be pre-treated before landfilling and, therefore, more inert. Simultaneously, activities carried out in modern waste management parks, other than landfilling will be intensified. Most of the waste management practices carried out in such parks are exposed to rainfall. Untreated stormwater is in many cases discharged directly to the recipient. It is thus important to regard stormwater runoff as a significant potential form of water pollutant transport.

This paper addresses some constraints faced when modelling the water flows and interactions with solid waste fractions in a modern landfill site such as:

- Water flow through the waste body (leachate generation) and pollutants transport;

- Water flow through the unsaturated zone that separates the landfill bottom and the aquifer and groundwater contamination;

- Stormwater runoff and pollutant transport from surfaces used for storage, sorting and treatment (e.g.: composting, etc) of waste. 


\section{MODELLING THE LEACHATE GENERATION}

The simplest estimates of landfill leachate production are obtained using the water balance method. Even though this is the most practicable option, the water balance method does not reproduce observed patterns of landfill leachate production. More complex analytical and numerical models have been widely used in many countries (Marques and Manzano, 2003) to predict percolation rates beneath landfills, such as the US EPA Hydrological Evaluation of Landfill Performance HELP V. 3.0 (Schroeder al., 1994), PREFLO model (Ugoccioni and Zeiss, 1997) and MOBYDEC model (Guyonnet al., 1998), among others. HELP model, for instance, goes into more details in trying to account for the complexity of the system than most water balance models. HELP is a quasi-two-dimensional (2-D) deterministic model. It handles one-dimensional (1-D) vertical drainage and 1-D lateral drainage coupled at the base of lateral drainage layers above the base liner/barrier system. Surface hydrological processes include snowmelt, interception of rainfall by vegetation, surface runoff and evaporation. Subsurface hydrological processes include: evaporation from a soil profile, plant transpiration, unsaturated vertical drainage, soil barrier/liner percolation, geo-membrane leakage and saturated lateral drainage. HELP predicts leachate flow according to the 1-D Darcian flow through homogeneous solid matrix layer. This is a limited approach, since it does not consider preferential pathway (channel) flow. It has been emphasized in the literature that a 2-D flow regime of channelled and matrix flows may better describe water flow inside a MSW landfill. Such theory is supported by the observation that the predicted breakthrough time given by HELP for flow inside a MSW landfill is usually greater than that observed (Uguccioni and Zeiss, 1997). It has been emphasized that in landfill leachate modelling, as in most modelling, the complexity of the selected model should be consistent with the amount and quality of the available input data (Marques, 2000). Therefore, selection of an appropriate model should be made on a case-by-case basis.

How appropriate are these calculations and consequently the designed leachate collection and treatment systems for the highly diverse climate conditions is a difficult question to answer, particularly in developing countries where no time series data of leachate generation is available for checking the estimated values against the real values (Marques and Manzano, 2003). In many cases, the systems constructed for collection, storage and treatment of the leachate are under or overestimated to a large extent, which certainly compromises the cost/effectiveness of these projects or increases significantly the risk of pollution of both superficial and groundwater resources.

\section{MODELLING THE GROUNDWATER CONTAMINATION BY LEACHATE}

When modelling the groundwater contamination by leachate, possible leachate migration pathways must be identified from the conceptual model. The corresponding risk of groundwater contamination is evaluated by considering components in sequence, with the contaminant release from the waste (source) providing the input flux to the pathway and the contaminant flux from the pathway providing the contaminant load to the groundwater (receptor). The source is modelled as a declining source term. The pathway is taken to be an advection-dispersion-retardation-decay transport model. Onedimensional models contrast with a full, distributed numerical model of the contaminant 
migration. By adopting a 1-D representation of the transport pathway, the model is generally conservative, not taking credit for the dilution associated with spreading into a larger volume of the hydrogeological system. Distributed numerical modelling (e.g.: MODFLOW based transport codes) is usually only justified where the parameters describing the geometrical distribution of the flow are well known. Usually, there are fewer data with which to describe the contaminant transport, therefore, three dimensional model of the contaminant transport processes is not justified.

Time series of parameters of groundwater quality can be properly treated by statistical methods to identify trends (Gilbert, 1987). Probabilistic risk assessment, and in particular, the Monte Carlo approach (a simple implementation of this method) addresses the case where a parameter may have a range of values. Instead of assigning a single value to each parameter, a combination of data and expert judgement are used to define the distribution of possible values that the parameter might take. This allows account to be taken of the possibility that a given parameter might, at this site, have a particularly low or high value, but would also incorporate the knowledge of how likely these extreme values are. The highest output risk would be associated with the worst values of all parameters with the range of values - analogous to a "worst case" scenario. This is now recognised as an inappropriate basis for decisions on many issues involving risk. Instead, a judgement needs to be made on an acceptable level of risk considering both the consequence and the likelihood of that consequence. A measure of the risk to consider is the consequence associated with the 95 percentile confidence interval. In this case one is $95 \%$ confident that the impact will be less than a certain value.

Groundwater contamination models can be particularly sensitive to two parameters: (i) the field capacity of the waste and (ii) the vertical hydraulic conductivity of the glacial till (Marques and Hogland, 2003). Given a lack of sufficient data on an appropriate field capacity to select for the different waste types and the vertical hydraulic conductivity of the unsaturated zone between the landfills and the aquifers the answers obtained with these models show a large range of uncertainty.

\section{MODELLING THE STORMWATER RUNOFF AND POLLUTANT TRANSPORT FROM WASTE STORAGE, RECYCLING AND TREATMENT SURFACES}

Stormwater runoff from areas where waste is stored, processed or treated is invariably polluted to some extent. Stormwater can become contaminated by a wide range of pollutants when solid materials wash off or dissolve into water. Wastes spilled, leaked, or lost from waste management areas may build up in soils or on other surfaces and be carried away by runoff following rainfall. The volume and composition of stormwater discharges associated with waste management activities depend on a number of factors, including the activities occurring at the facility, the regional characteristics of precipitation, and the degree of surface imperviousness. The following activities can be identified as major potential sources of pollutants in stormwater discharges associated with waste management:

- loading and unloading of waste or recyclable materials; 
- composting of organic waste;

- outdoor storage of recyclable material, waste as fuel and residues from sorting, composting, recycling, and incineration;

- dust or particulate generating processes, such as mechanical sorting and shredding;

- dust or particulate generating processes related to traffic/wear by trucks/machinery, e.g., from brake linings, spills and leaks of motor oil and grease, vehicle exhaust, wear of tires, corrosion of vehicles, and road salt (deicing);

- corrosion of building materials (e.g., roof plating); and

- leaching of pollutant substances from machine and car washing.

Annual precipitation and stormwater runoff estimated for each assessed area are needed. In order to calculate stormwater runoff, the excess rainfall must be estimated, that is, the rainfall that is neither retained on the land surface nor infiltrates into the soil. After flowing across the surface, excess rainfall becomes direct runoff under the assumption of Hortonian overland flow (Chow et al. 1988). The difference between the observed total rainfall and the excess rainfall is termed abstraction, or loss. Abstraction includes: a) storage in depressions on the ground surface as water accumulates in hollows; b) interception of rainfall on vegetation above the ground; and c) infiltration into the soil. Calculations for impervious asphalt surfaces and bare soil with low permeability (for instance, compacted clay) exclude abstraction of types b) and c). The losses in these cases are the consequence of depression storage in irregularities on the surfaces, and depend on the type of material used and the age of the road. It has been shown, for instance that about half of the stormwater volume that run off asphalt surfaces, run off gravel surfaces in a waste management park in Sweden (Marques and Hogland, 2000). This illustrates the influence of the pavement on pollutant load transport. The uncertainty here is associated to the estimation of abstractions $(\mathrm{mm})$ in different surfaces and the concentration of pollutants $(\mathrm{mg} / \mathrm{l})$ taken to calculate the pollutant load (ton/year).

\section{CONCLUSIONS}

As usual, modelling is a powerful tool but as an approximation of reality, it must be taken with caution. Water and waste interactions in waste management parks and risk assessment of contamination of recipient water bodies - surface and/or ground water - are dependent to a large extent from modelling. However, the results must be taken with caution and supported by field data. Better knowledge about field parameters, better monitoring programmes and the construction of database are expected to contribute for modelling improvement.

\section{REFERENCES}

[1] Chow, V.T., Maidment, D.R. \& Mays, L.W. 1988. Applied Hydrology. Singapore: McGraw-Hill International.

[2] Gilbert, R.O. 1987. Statistical Methods for Environmental Pollution Monitoring. New York, USA: Van Sostrand Reinhold Ed. 
KALMAR ECO-TECH'03

Bioremediation and Leachate Treatment

KALMAR, SWEDEN, November 25-27, 2003

[3] Guyonnet D, Didier-Guelorget B, Provost G, Feuillet C. 1998. Accounting for water storage effects in landfill leachate modelling. Waste Management and Research 16(3):285-295. DOI: https://doi.org/1 0.1177/0734242X9801600310

[4] Marques, M. 2000. Solid Waste and the Water Environment in the New European Union Perspective: Process Analysis Related to Storage and Final Disposal. Stockholm: Department of Chemical Engineering and Technology, Royal Institute of tTechnology, 177pp.

[5] Marques, M.; Hogland, W. 2003. Groundwater Risk Assessment for different waste stream disposal: Spillepeng Landfill, Sweden. In: Ninth International Waste Management and Landfill Symposium, Sardinia. Cagliari, Eurowaste.

[6] Marques, M; Manzano, M. 2003. Hydrological performance of sanitary landfills in different climatic regions in Brazil. In: Ninth International Waste Management and Landfill Symposium, Sardinia. Cagliari, Eurowaste.

[7] Marques, M., Hogland, W. 200t. Stormwater runoff and pollutants transport related to different activities carried out in a modern waste disposal site. Waste Management and Research, Copenhagen, v. 19: 20-35.

[8] Schroeder P, Dozier T, Zappi P, McEnroe M, Sjostrom J, Peyton R. The hydrologic evaluation of landfill performance (HELP) model. Documentation for version 3.0. Report EPA/600/R-94/168b, Cincinnati, OH, USA: Risk Reduction Engineering Laboratory, Office of Research and Development, US Environmental Protection Agency, 1994.

[9] Uguccioni M, Zeiss C. 1997. Comparison of two approaches to modelling moisture movement through municipal solid waste. Journal of. Environmental Systems 25(1):41-63. DOI: https://doi.org/10.2190/DD37-EG9W-PFFD-WJM7 